
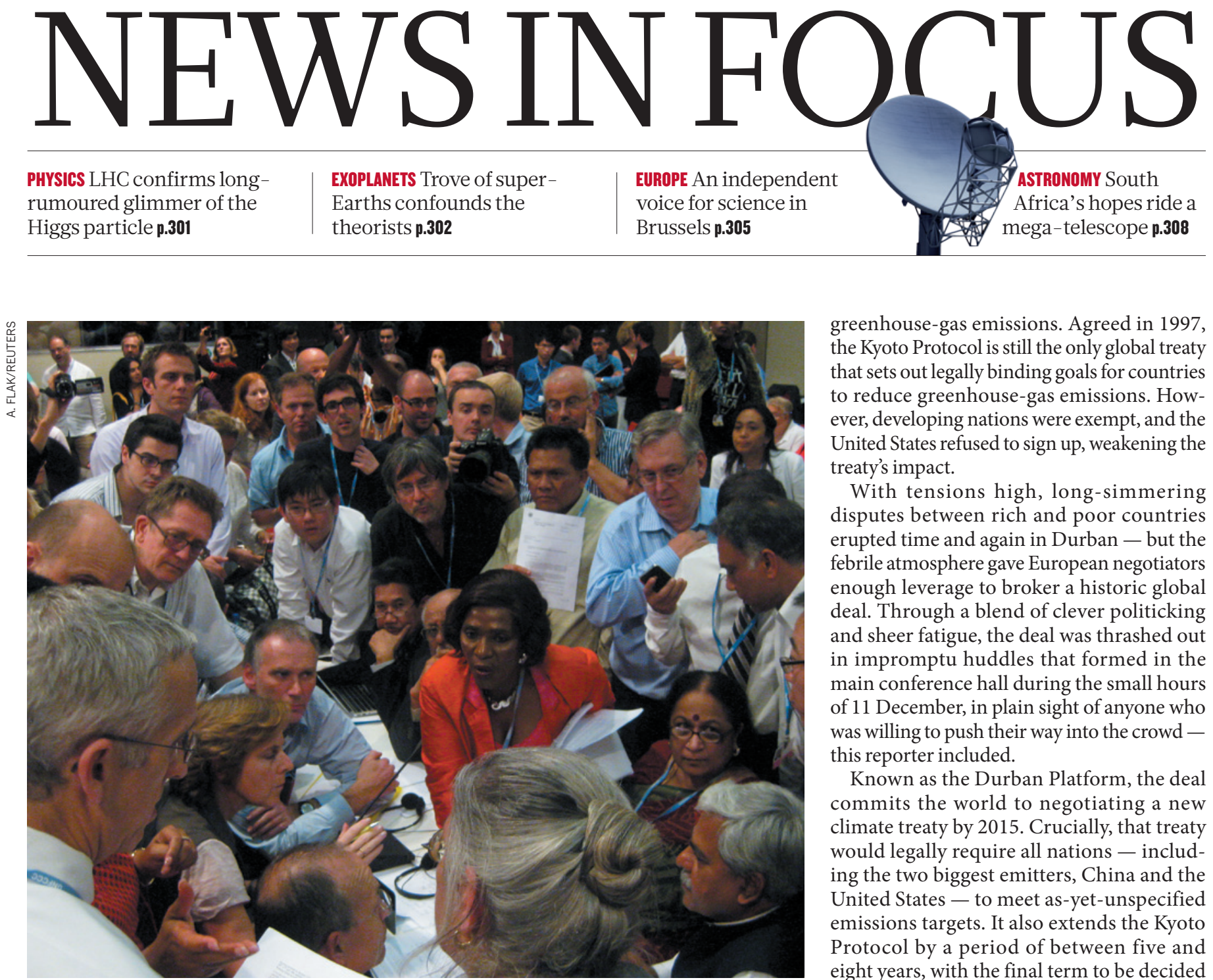

Europe's climate commissioner, Connie Hedegaard (seated left), negotiates with India's environment minister, Jayanthi Natarajan (seated mid-right), in the early hours of 11 December in Durban, South Africa.

\title{
POLICY
}

\section{Durban maps path to climate treaty}

\section{Marathon talks enable Europe to break deadlock over global-warming deal with major greenhouse-gas emitters.}

\section{BY JEFF TOLLEFSON IN DURBAN}

$\mathrm{I}$ $\mathrm{n}$ the darkest hours of the international climate-change negotiations in Durban,

South Africa, last week, there was talk of postponing a decision altogether. But one question always came up: would more time really make a difference? After all, the issues facing negotiators have not changed in years, and the scientific evidence for the potential impacts of anthropogenic climate change just keeps getting stronger.

The first round of greenhouse-gas reduction commitments under the Kyoto Protocol will expire at the end of 2012, adding to the pressure on policy-makers to tackle the problem and leaving Durban as the last, best chance to establish a fresh road map to curb

greenhouse-gas emissions. Agreed in 1997, the Kyoto Protocol is still the only global treaty that sets out legally binding goals for countries to reduce greenhouse-gas emissions. However, developing nations were exempt, and the United States refused to sign up, weakening the treaty's impact.

With tensions high, long-simmering disputes between rich and poor countries erupted time and again in Durban - but the febrile atmosphere gave European negotiators enough leverage to broker a historic global deal. Through a blend of clever politicking and sheer fatigue, the deal was thrashed out in impromptu huddles that formed in the main conference hall during the small hours of 11 December, in plain sight of anyone who was willing to push their way into the crowd this reporter included.

Known as the Durban Platform, the deal commits the world to negotiating a new climate treaty by 2015 . Crucially, that treaty would legally require all nations - including the two biggest emitters, China and the United States - to meet as-yet-unspecified emissions targets. It also extends the Kyoto Protocol by a period of between five and eight years, with the final term to be decided at the next annual conference of the United Nations Framework Convention on Climate Change in Doha, Qatar, at the end of 2012. The European Union (EU) has already promised to register its existing emissions pledges under the extended protocol, as has a handful of other countries. Canada, however, has been unable to meet its Kyoto commitments, and announced on 12 December that it would formally withdraw from the protocol.

Many observers had expected the conference to continue down the path towards voluntary climate commitments that was paved at the climate summit in Copenhagen two years ago (see Nature 479, 291-292; 2011). Instead, the Durban Platform shifts countries towards a legally binding agreement, which would come into force in 2020. "These really were very high-stakes negotiations over competing visions of the world," says Alden Meyer, who heads climate policy for the Union of Concerned Scientists in Washington DC.

\section{DNATURE.COM}

Read more analysis from the summit at: go.nature.com/dw9pu2
Despite the celebratory atmosphere, the platform represents an exercise in legalese that does little or nothing 


\section{THE GIGATONNE GAP}

By the time a new treaty to limit emissions comes into force in 2020 , the world will have diverged further from the path needed to limit warming to $2^{\circ} \mathrm{C}$ by 2100 , according to an analysis by Climate Action Tracker.

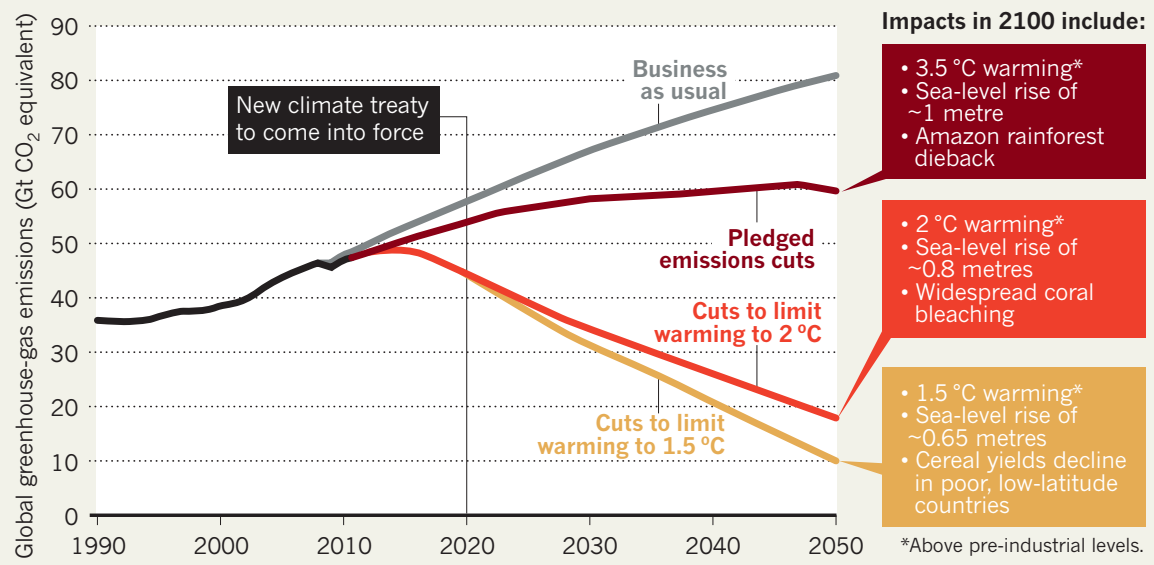

- to reduce emissions, and defers action for almost a decade. The stated goal of the talks was to limit global warming to $2{ }^{\circ} \mathrm{C}$, although many developing nations and small-island states have advocated a target of $1.5^{\circ} \mathrm{C}$. But the latest analysis of current pledges from climate scientists advising delegates in Durban suggests that the world is on course to see $3.5^{\circ} \mathrm{C}$ of warming this century (see 'The gigatonne gap').

Countries such as Venezuela protested against the proposed deal, noting that past emissions by the United States and Europe will drive much of this warming. They argued that rich countries have refused to reduce their own emissions, and are now demanding that poor countries sacrifice economic development to make carbon cuts. But other developing countries, acknowledging that most future emissions growth will come from once-poor nations, were willing to sign up. Early in the summit, Brazil and South Africa said that they would accept binding commitments under a new treaty. As the final negotiations over wording began, observers said that China and the United States also acquiesced. By the morning of 11 December, India was the main holdout.

India's environment and forests minister, Jayanthi Natarajan, gave an impassioned speech invoking the original 1992 Framework Convention on Climate Change, which stated that countries have "common but differentiated responsibilities" for tackling global warming - language that was not part of the new proposal. "Does climate change mean you give up equity?" Natarajan asked. "India will never be intimidated by threats or any kind of pressure like this."

After objecting to stronger wording, India finally agreed to pursue talks towards a "protocol, legal instrument or an agreed outcome with legal force". Connie Hedegaard, the EU commissioner for climate change, who was instrumental in pushing for a road map to a legally binding treaty, said the outcome was a "good and strong result". Luiz Alberto

\section{"There is going to be some tough bargaining ahead."}

Figueiredo Machado, Brazil's lead negotiator, called the agreement a significant step. "I am relieved that we have what we came here to get," he said.

Island states threatened by rising seas, such as Grenada and Papua New Guinea, had hoped for more immediate, aggressive steps. Kevin Conrad, the representative for Papua New Guinea in the negotiations, lays part of the blame for inaction on the ongoing global financial crisis. Economic woes have certainly diverted attention from the climate threat and, in the United States, emboldened right-wing politicians who have blocked President Barack Obama's climate agenda. The political situation may be no more favourable when treaty negotiations culminate in 2015, but "we need to start somewhere and then begin a process to ramp things up", says Conrad. Fearing that the Durban agreement could lock in weak commitments until 2020, some countries plan to use a formal scientific review built into the process to push for additional, early emissions cuts.

Negotiators did, however, make some progress in establishing a Green Climate Fund designed to help developing countries cope with global warming, although the talks failed to identify any sources of new funding. Industrialized nations had agreed at previous meetings to boost funding for developing countries to US $\$ 100$ billion annually by 2020 ; now they need to begin allocating the money.

The talks also moved closer to establishing a system that would allow payments to countries that reduce carbon emissions by preventing deforestation, which accounts for roughly $15 \%$ of global emissions. Negotiators settled some technical details about how nations will calculate their emissions, and launched a process to explore how the funding system will work.

The agreement also modified the Clean Development Mechanism, by which countries can sell carbon credits for projects that lower greenhouse-gas emissions, such as renewable energy. The mechanism, negotiated in Kyoto, allows developing countries to build up their green infrastructure, and sell the resulting credits to more developed nations. In Durban, negotiators extended the mechanism to include projects that capture and store carbon emissions from power plants, allowing Western countries to finance these plants more cheaply in India or China. The agreement also requires industrialized countries to accept long-term liability for the projects, with $5 \%$ of the carbon credits being set aside to account for any leakage of stored greenhouse gases in the 20 years after they are buried.

And in answer to growing demands to consider agriculture as a separate sector within the UN climate framework (see Nature 479, $279 ; 2011)$, the agreement establishes a technical body to investigate the issue and report back at the next meeting in Doha.

That meeting will be the first test of whether the Durban Platform really can work as a global road map for climate-change action. "There is going to be some tough bargaining ahead," says Meyer. "But I'm a lot more hopeful now than I was a couple of days ago." - SEE EDITORIAL P.292

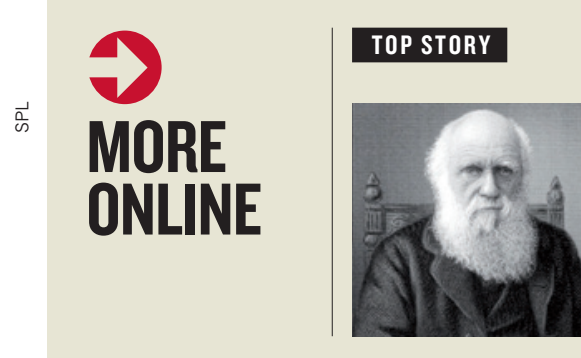

Shipping timetables debunk Darwin plagiarism accusations go.nature.com/ xoqp $2 p$

\section{MORE NEWS}

- Lukewarm reception for UK government's life-sciences investment go.nature.com/oexlz4

- Method predicts size of fracking earthquakes go.nature.com/rk7luf

- Mammoth femur yields first ancient proteome go.nature.com/htvblo

\section{AUDIO}

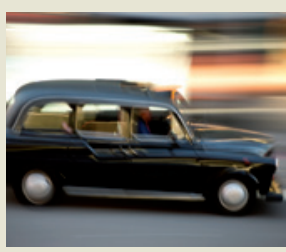

How having 'the Knowledge' enlarges your brain go.nature.com/ pbtsge 